\title{
The difference in development rate of rye in relation to the number of spikelets per ear
}

\author{
R. F. HOOGLAND
}

Institute for Biological and Chemical Research on Field Crops and Herbage (I.B.S.), Wageningen, Netherlands

\begin{abstract}
Summary
In winter rye plants of the Petkuser and Zelder varieties four groups of plants were distinguished having $11,12,13$ and 14 leaves on the main axis. Within these groups it was possible to distinguish sub-groups with a difference in rhythm of emergence, viz. a rapid rate after winter (with a previous slow rate), and a slow rate after winter (with a rapid rate during the youth). Apparently a low rate of emergence after winter goes together with large upper-stalk leaves, a slightly higher number of spikes per ear, longer upper internodes and longer leaf sheats of the upper leaves.

It was also found that a larger total number of stalk leaves is accompanied by a larger total leaf-surface area, possibly a slightly higher number of spikelets per ear, and a greater average stalk length.

This pattern does not fully reflect the rectilinearity because not all possible categories have been distinguished. But the simplicity of the pattern in question (FIG. 8) shows that the rectilinear aspect is a general characteristic, one that does not merely relate to the leaves but to other parts of the plant as well.
\end{abstract}

\section{Introduction}

The number of leaves ultimately formed by rye plants depends, among other factors, on the hereditary predisposition of the plants (HooglaND, 1961, 1962). In order to examine whether this leaf number has any effects on plant productivity an investigation was made into the relationship between leaf number, leaf area and ear emergence (HooglaNd, 1964). It was found that a larger number of leaves went together with a larger leaf area and a larger number of spikelets in the ear. These relationships are examined in more detail in the present article, closer attention being paid to the above-mentioned difference in rhythm of leaf emergence. The relationships between leaf surface area, length of the accompanying stalk internode and leaf sheath are also discussed.

\section{Method of research}

The investigation was carried out in 1962-63, following the same method as that employed in 1961-62. The date of sowing was advanced to 25th September, 1962 and the number of observations were increased by determining the length of the internodes and leaf sheaths as far as possible. Since the number of measurements have to be kept to the minimum to prevent damage to the plants, the length of the leaf

Received for publication 29th June, 1964.

Neth. J. agric. Sci., Vol. 12 (1964) No. 4 (November) 
sheath (usually already present) of the leaf which is to be measured showed an indication when the leaf ligula had emerged, so that the date on which the leaves were fully grown could be more readily calculated.

The surface area of the leaves was calculated by multiplying the length by the width taken to the nearest $\mathrm{mm}$. The calculation of the width is particularly subject to reading errors. As the plants should be touched as little as possible these values are rather to be considered as reasonable estimates. Although in transition cases, e.g. when the correct is $4,5 \mathrm{~mm}$, the reading result may be $4 \mathrm{~mm}$ or $5 \mathrm{~mm}$, the average result is very satisfactory despite such inaccuracy.

According to ANIKIEv and Kutuzov (1961) the actual leaf area is best calculated by again multiplying the length $\times$ width product by $2 / 3$, but since we are here concerned with relative figures this method was not employed.

Of the 125 grains sown of each variety, 112 plants of the Petkuser variety and 109 of the Zelder variety remained for complete observation.

\section{Results}

The aim envisaged, i.e. to obtain a greater distribution of the total number of leaves by advancing the sowing date, was not achieved. Although there was a greater number of leaves, the number of groups proved to be the same as in the previous year. There were plants that were finally found to have produced $11,12,13$ and 14 leaves (previous year 10,11, 12 and 13 respectively). TABLE 1 lists the number of plants, as well as the data on leaf-surface area, the number of spikelets and the mean date on which the leaves of a particular serial number were fully grown.

TABLE 1. Average leaf surface $\left(\mathrm{mm}^{2}\right)$, leaf number and average number of spikelets; in brack

\begin{tabular}{|c|c|c|c|c|c|c|c|c|c|}
\hline \multirow{2}{*}{\multicolumn{2}{|c|}{ Varieties }} & \multirow{2}{*}{$\begin{array}{l}\text { Number } \\
\text { of plants }\end{array}$} & \multicolumn{7}{|c|}{ Average leaf area in $\mathrm{mm}^{2}$ (leaf sequence $1-14$ ) } \\
\hline & & & 1 & 2 & 3 & 4 & 5 & 6 & 7 \\
\hline \multicolumn{10}{|c|}{$11-1$ aves group } \\
\hline Petkuser & $\ldots \ldots \ldots$ & 3 & $\begin{array}{c}434 \\
(16 / 10)\end{array}$ & $\begin{array}{c}577 \\
(21 / 10)\end{array}$ & $\begin{array}{c}1020 \\
(3 / 11)\end{array}$ & $\begin{array}{c}1404 \\
(20 / 11)\end{array}$ & $\begin{array}{l}1261 \\
(4 / 2)\end{array}$ & $\begin{array}{c}932 \\
(14 / 3)\end{array}$ & $\begin{array}{l}160 \\
(28 /\end{array}$ \\
\hline Zelder & $\cdots$ & 7 & $\begin{array}{c}406 \\
(16 / 10)\end{array}$ & $\begin{array}{c}610 \\
(16 / 10)\end{array}$ & $\begin{array}{c}1059 \\
(2 / 11)\end{array}$ & $\begin{array}{c}1277 \\
(18 / 11)\end{array}$ & $\begin{array}{l}1149 \\
(28 / 1)\end{array}$ & $\begin{array}{c}921 \\
(11 / 3)\end{array}$ & $\begin{array}{l}150 \\
(28 /\end{array}$ \\
\hline \multicolumn{10}{|c|}{$12-1$ e a es group } \\
\hline Petkuser & $\ldots \ldots \ldots$ & 47 & $\begin{array}{c}342 \\
(16 / 10)\end{array}$ & $\begin{array}{c}522 \\
(21 / 10)\end{array}$ & $\begin{array}{c}811 \\
(3 / 11)\end{array}$ & $\begin{array}{c}1040 \\
(20 / 11)\end{array}$ & $\begin{array}{c}977 \\
(20 / 1)\end{array}$ & $\begin{array}{c}778 \\
(15 / 3)\end{array}$ & $\begin{array}{l}118 \\
(28 /\end{array}$ \\
\hline Zelder & & 53 & $\begin{array}{c}444 \\
(16 / 10)\end{array}$ & $\begin{array}{c}717 \\
(16 / 10)\end{array}$ & $\begin{array}{c}1037 \\
(3 / 11)\end{array}$ & $\begin{array}{c}1298 \\
(12 / 11)\end{array}$ & $\begin{array}{l}1296 \\
(1 / 1)\end{array}$ & $\begin{array}{c}973 \\
(10 / 3)\end{array}$ & $\begin{array}{r}122 \\
(26 /\end{array}$ \\
\hline \multicolumn{10}{|c|}{ 13-1 e a es group } \\
\hline Petkuser & $\ldots \ldots \ldots$ & 48 & $\begin{array}{c}350 \\
(16 / 10)\end{array}$ & $\begin{array}{c}521 \\
(20 / 10)\end{array}$ & $\begin{array}{c}782 \\
(4 / 11)\end{array}$ & $\begin{array}{c}994 \\
(16 / 11)\end{array}$ & $\begin{array}{l}1043 \\
(4 / 1)\end{array}$ & $\begin{array}{c}859 \\
(27 / 2)\end{array}$ & $\begin{array}{r}93 \\
(20 /\end{array}$ \\
\hline Zelder & & 44 & $\begin{array}{c}424 \\
(16 / 10)\end{array}$ & $\begin{array}{c}651 \\
(16 / 10)\end{array}$ & $\begin{array}{c}940 \\
(2 / 11)\end{array}$ & $\begin{array}{c}1180 \\
(6 / 11)\end{array}$ & $\begin{array}{c}1250 \\
(20 / 12)\end{array}$ & $\begin{array}{c}933 \\
(3 / 3)\end{array}$ & $\begin{array}{l}101 \\
(22 /\end{array}$ \\
\hline \multicolumn{10}{|c|}{ 14-leaves group } \\
\hline Petkuser & $\ldots \ldots \ldots$ & 14 & $\begin{array}{c}349 \\
(16 / 10)\end{array}$ & $\begin{array}{c}505 \\
(18 / 10)\end{array}$ & $\begin{array}{c}790 \\
(3 / 11)\end{array}$ & $\begin{array}{c}1001 \\
(10 / 11)\end{array}$ & $\begin{array}{c}1130 \\
(23 / 12)\end{array}$ & $\begin{array}{c}1022 \\
(22 / 2)\end{array}$ & $\begin{array}{r}87: \\
(17 /\end{array}$ \\
\hline Zelder & & 5 & $\begin{array}{c}457 \\
(15 / 10)\end{array}$ & $\begin{array}{c}602 \\
(15 / 10)\end{array}$ & $\begin{array}{c}903 \\
(4 / 11)\end{array}$ & $\begin{array}{l}1112 \\
(4 / 11)\end{array}$ & $\begin{array}{c}1334 \\
(20 / 12)\end{array}$ & $\begin{array}{c}1137 \\
(13 / 2)\end{array}$ & $\begin{array}{r}84^{\prime} \\
(15 /\end{array}$ \\
\hline
\end{tabular}


The figures shown for the date are averages of the dates on which the leaves in question were first found to be fully grown, where necessary corrected by means of an estimate of the number of days that had elapsed since full emergence.

\subsection{The rate and rhythm of leaf emergence}

Although there is a tendency for the last leaf to emerge somewhat later when the number of leaves increases (FIG. 1), this is of so little importance compared to the total period of leaf emergence that the average rate of emergence is necessarily higher according as more leaves are formed. It was found, however, that this average rate does not adequately typify the behaviour of the plants. Thus within the groups with a given, final number of leaves it is still possible to distinguish plants with an originally greater number of already emerged leaves than other plants, although the latter afterwards exhibit a high rate (the average emergence rate remaining substantially unchanged) (see TABLE 2 and FIG. 2). It was found that the date on which the two sub-groups could be most readily distinguished by the number of leaves was 14th March or a little earlier, viz. the first observation after a severe winter. Owing to the small number of plants such distinctions in emergence rhythm are impossible to make in the group of Petkuser and Zelder plants with 11 leaves, as also in the group of Zelder plants with 14 leaves. It can easily be seen that up to the 6th leaf the originally backward subgroup in the Petkuser group with 14 leaves is able to develop approximately the same rate as the originally rapid sub-group in the Petkuser group with 12 leaves.

TABLE 2 also shows that the average date of emergence of the last leaf is somewhat earlier in plants exhibiting a low rate in spring within the same group. Selection

rerages of measuring dates, i.e. of the dates on which the leaf was fully developed

\begin{tabular}{|c|c|c|c|c|c|c|c|c|c|}
\hline \multicolumn{8}{|c|}{ Average leaf area in $\mathrm{mm}^{2}$ (leaf sequence $1-14$ ) } & \multicolumn{2}{|c|}{ Number of spikelets } \\
\hline 8 & 9 & 10 & 11 & 12 & 13 & 14 & total & initiated & full-grown \\
\hline $\begin{array}{l}2599 \\
(8 / 4) \\
2330 \\
(8 / 4)\end{array}$ & $\begin{array}{c}3881 \\
(16 / 4) \\
3303 \\
(16 / 4)\end{array}$ & $\begin{array}{l}4240 \\
(23 / 4) \\
3763 \\
(22 / 4)\end{array}$ & $\begin{array}{l}2028 \\
(29 / 4) \\
2098 \\
(30 / 4)\end{array}$ & & & & $\begin{array}{c}19978 \\
18420\end{array}$ & $\begin{array}{l}35 \\
34,3\end{array}$ & 31,7 \\
\hline $\begin{array}{l}1847 \\
(7 / 4) \\
2022 \\
(5 / 4)\end{array}$ & $\begin{array}{c}2620 \\
(14 / 4) \\
2833 \\
(12 / 4)\end{array}$ & $\begin{array}{l}3108 \\
(20 / 4) \\
3455 \\
(18 / 4)\end{array}$ & $\begin{array}{c}2944 \\
(26 / 4) \\
3228 \\
(25 / 4)\end{array}$ & $\begin{array}{c}1201 \\
(1 / 5) \\
1475 \\
(30 / 4)\end{array}$ & & & 19998 & $\begin{array}{l}31,7 \\
33,8\end{array}$ & $\begin{array}{l}28 \\
31,5\end{array}$ \\
\hline $\begin{array}{l}1537 \\
(1 / 4) \\
1588 \\
31 / 3)\end{array}$ & $\begin{array}{l}2299 \\
(9 / 4) \\
2293 \\
(8 / 4)\end{array}$ & $\begin{array}{l}2870 \\
(15 / 4) \\
2955 \\
(15 / 4)\end{array}$ & $\begin{array}{c}3282 \\
(21 / 4) \\
3395 \\
(21 / 4)\end{array}$ & $\begin{array}{l}2736 \\
(27 / 4) \\
2863 \\
(26 / 4)\end{array}$ & $\begin{array}{l}1072 \\
(1 / 5) \\
1134 \\
(1 / 5)\end{array}$ & & $\begin{array}{l}19278 \\
20619\end{array}$ & 33,3 & $\begin{array}{l}20 \\
30,9\end{array}$ \\
\hline $\begin{array}{l}1274 \\
29 / 3) \\
1206 \\
27 / 3)\end{array}$ & $\begin{array}{l}1984 \\
(6 / 4) \\
1758 \\
(6 / 4)\end{array}$ & $\begin{array}{l}2613 \\
(13 / 4) \\
2382 \\
(9 / 4)\end{array}$ & $\begin{array}{c}3271 \\
(19 / 4) \\
2976 \\
(17 / 4)\end{array}$ & $\begin{array}{c}3343 \\
(24 / 4) \\
3217 \\
(22 / 4)\end{array}$ & $\begin{array}{c}2616 \\
(28 / 4) \\
2613 \\
(29 / 4)\end{array}$ & $\begin{array}{c}852 \\
(3 / 5) \\
939 \\
(2 / 5)\end{array}$ & 21625 & 34,6 & 31,3 \\
\hline
\end{tabular}


Fig. 1. Leaf-formation rhythm in the Petkuser and Zelder varieties

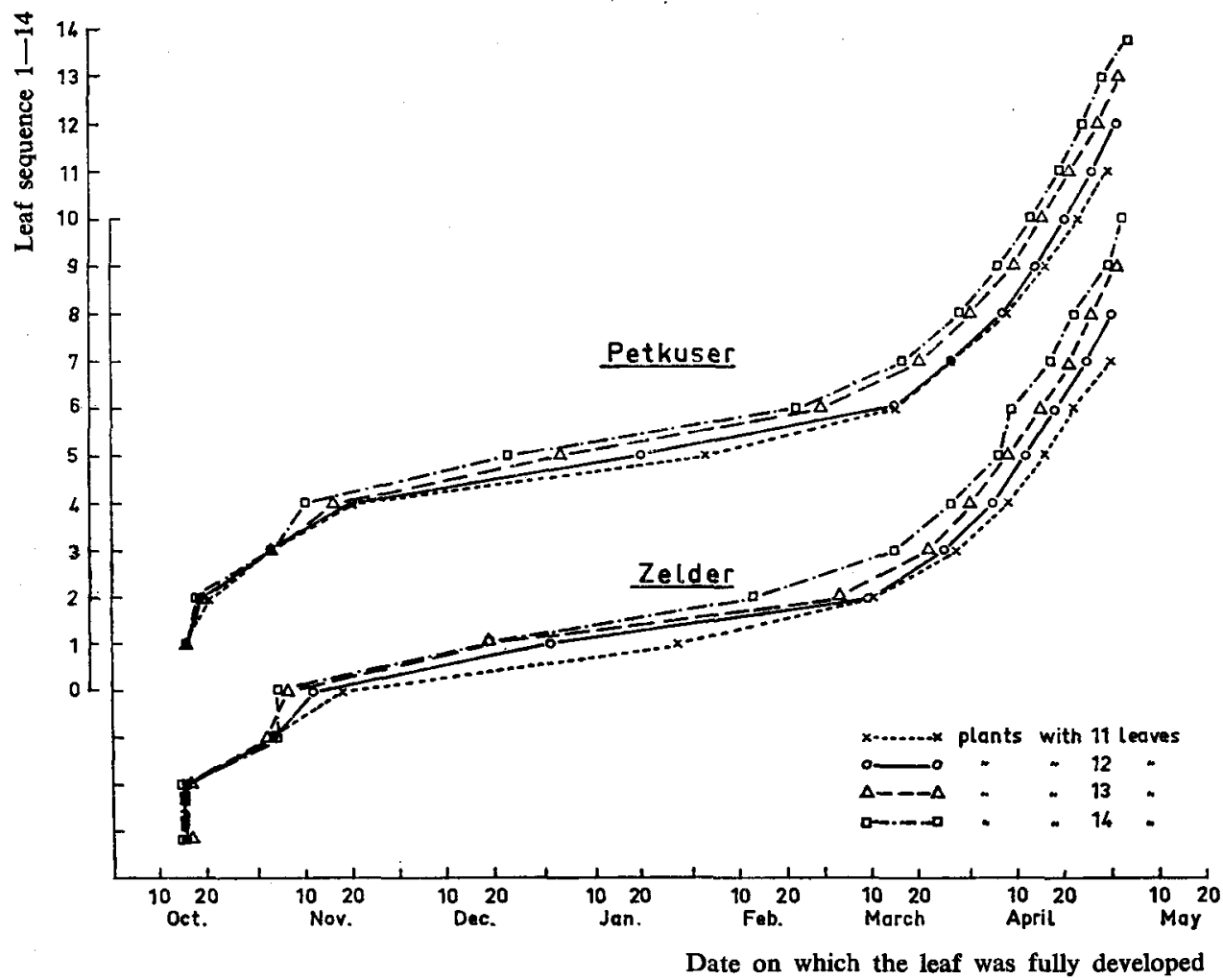

tests have shown that this type of difference in rhythm of leaf emergence is also hereditary, as in some families this difference becomes a permanent character. The tests have also shown that after four years of continuous selection it is possible to considerably advance the date of heading.

\subsection{The leaf surface area}

Although the total surface area as well as the average surface area per leaf (TABLE 1) are greater than in the previous year, viz. :

total leaf area of main axis $\quad 11.200$ to $17.300 \mathrm{~mm}^{2} \quad 17.400$ to $21.600 \mathrm{~mm}^{2}$ average area per leaf $\quad 1.121$ to $1.330 \mathrm{~mm}^{2} \quad 1.450$ to $1.660 \mathrm{~mm}^{2}$

the differences per group are considerably smaller.

TABLE 3 shows the average surface areas of the successively emerging leaves for the groups with the same leaf number, and within these groups the sub-groups of varying emergence rhythm, referred to in 3.1. FiG. 3 shows the trend of the leaf surface area.

It can be seen from the above that there is a remarkable difference in both the size of the last two leaves and their rhythm of emergence after the winter. The last two 
DIFFERENCE IN DEVELOPMENT RATE OF RYE IN RELATION TO NUMBER OF SPIKELETS PER EAR

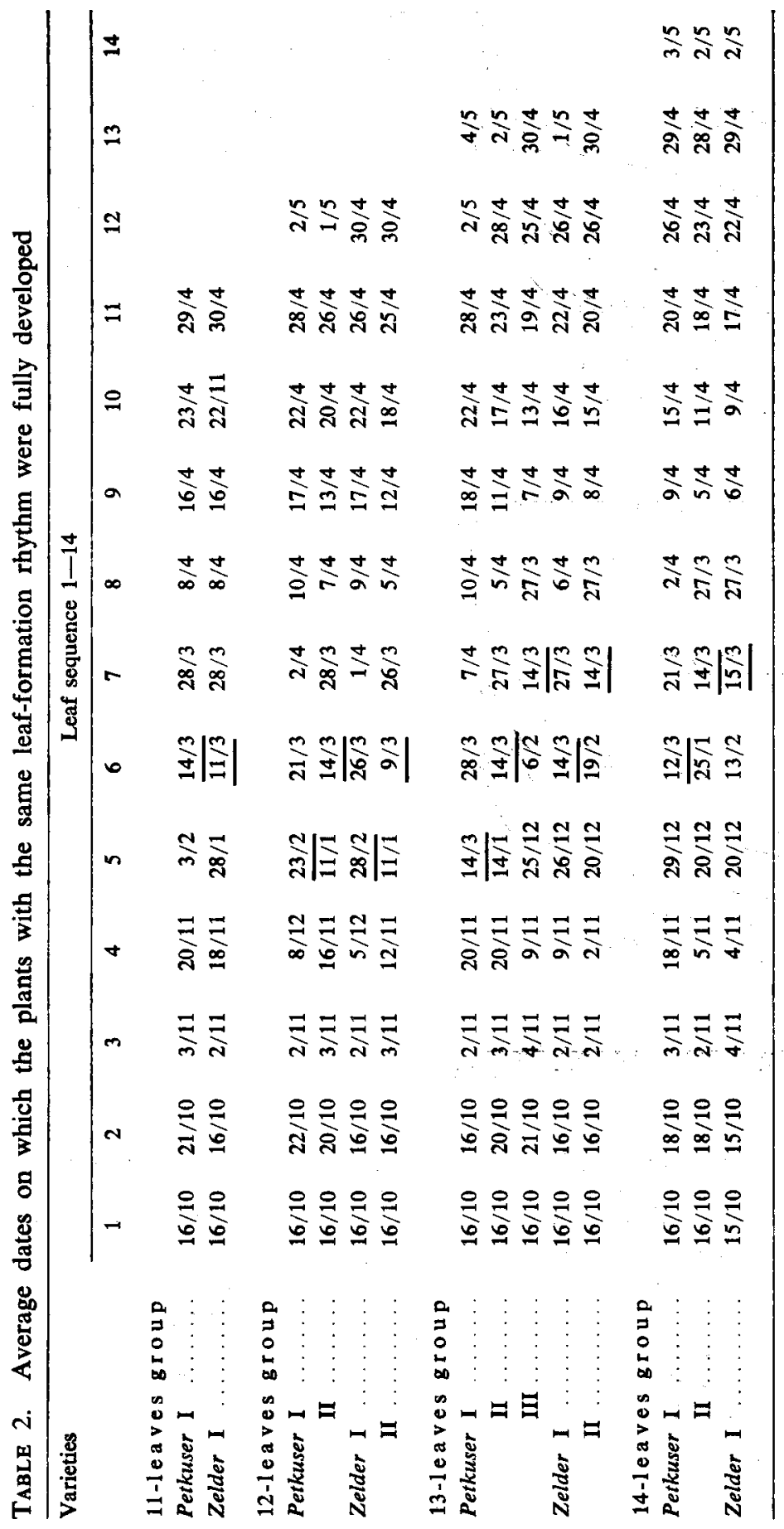

Neth. J. agric. Sci., Vol. 12 (1964) No. 4 (November) 


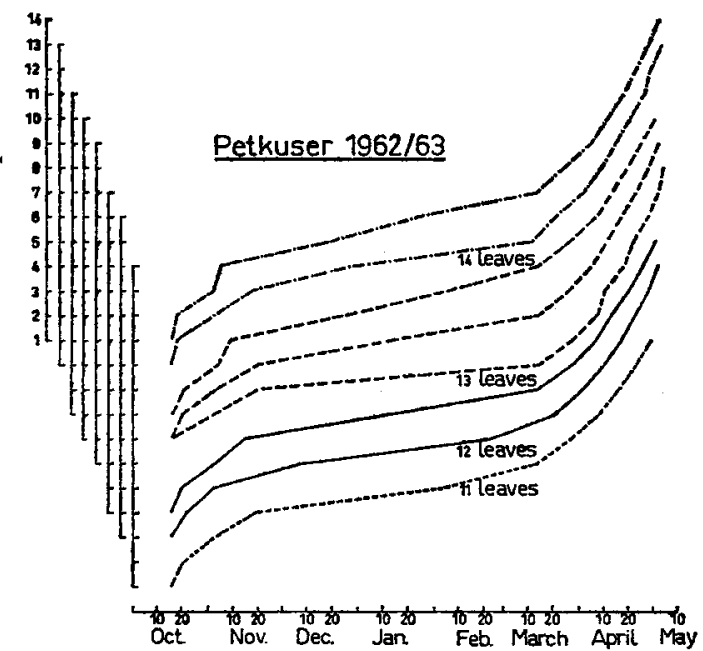

Date on which the leaf was fully developed

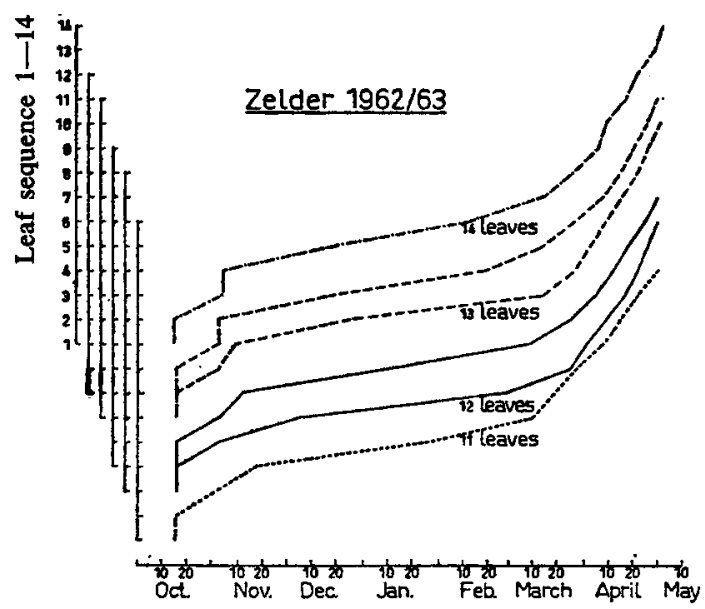

Date on which the leaf was fully developed
FIG. 2

Leaf-formation rhythm of plants with the same emergence rhythm in the Petkuser and Zelder varieties (in the groups represented by more than one line the lower lines relate to sub-groups with an initially slow leaf formation; at a later stage there is a catch-up effect)

leaves of plants with 13 leaves are significantly larger in plants with a slow emergence rhythm after the winter than in plants with a rapid emergence rhythm (level of significance at Petkuser $1 \%$, at Zelder $5 \%$ ). A low emergence rate after the winter, which is particularly the case when there are a small number of leaves, goes together with large upper-stalk leaves; a rapid emergence rate means small leaves. Since a rapid emergence rate after the winter is usually accompanied by a slow emergence rate before the winter and vice versa, the overall trend of the successive leaf sizes of the two sub-groups within the groups with a given number of leaves is also unequal (FIG. 4). It can be clearly seen from FIG. 5, in which the surface area of each leaf is plotted against the sum, that the site of the kink due to the small area of the first leaf measured after the winter depends on the leaf-emergence rhythm in the autumn. There are indications that this kink denotes the commencement of stalk initiation. 


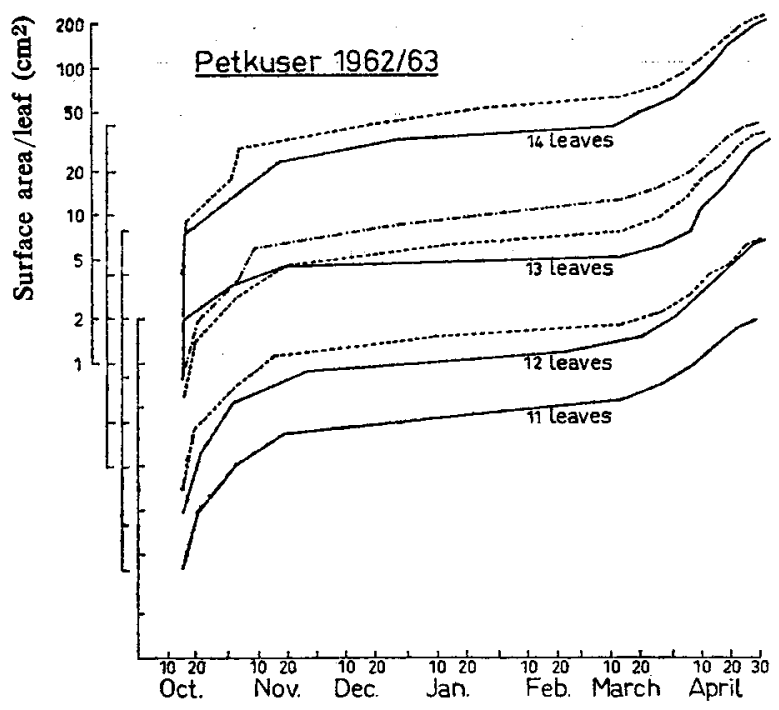

FIG. 3

Sum total (summation) of leafsurface area $\left(\mathrm{cm}^{2}\right)$ of plants with the same emergence rhythm in the Petkuser and Zelder varieties (ordinate log. scale); for groups represented by more than one line see FIG. 2

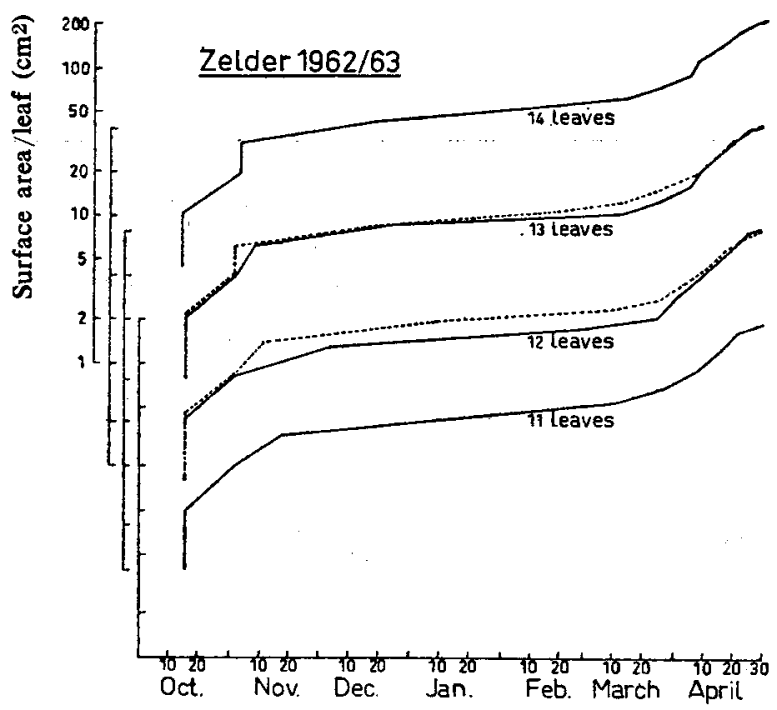

\subsection{The number of spikelets per ear}

TABLE 3 also lists the numbers of spikelets initiated in the various groups. It can be seen that in this year there is not the same close correlation between the number of spikelets and the total leaf-surface area as in 1962. Ignoring the group with 11 leaves owing to the small number of plants, the only noticeable increase is in Petkuser. As noted above (3.2.) there is not the same increase in leaf-surface area as in the previous year, although there is an indication that the number of spikelets initiated 
R. F. HOOGLAND

TABle 3. Average leaf surface $\left(\mathrm{mm}^{2}\right)$, leaf number and average number of spikelets; classific

\begin{tabular}{|c|c|c|c|c|c|c|c|c|}
\hline \multirow[t]{2}{*}{ Varieties } & & \multirow{2}{*}{$\begin{array}{l}\text { Number } \\
\text { of plants }\end{array}$} & \multicolumn{6}{|c|}{ Average leaf area in $\mathrm{mm}^{2}$ (leaf sequence $1-14$ ) } \\
\hline & & & 1 & 2 & 3 & 4 & 5 & 6 \\
\hline \multicolumn{9}{|c|}{$11-$ le aves group } \\
\hline Petkuser I & $\ldots \ldots$ & 3 & 434 & 577 & 1020 & 1404 & 1261 & 932 \\
\hline Zelder .... & $\ldots \ldots \ldots$ & 7 & 406 & 610 & 1059 & 1277 & 1149 & $\overline{921}$ \\
\hline \multicolumn{9}{|c|}{ 12-1eaves group } \\
\hline \multirow{2}{*}{$\begin{aligned} & \text { Petkuser } \text { I } \\
& \text { II }\end{aligned}$} & $\ldots \ldots$ & 8 & 257 & 374 & 703 & 936 & 696 & 860 \\
\hline & $\ldots \ldots$ & 39 & 353 & 543 & 829 & 1056 & $\overline{1021}$ & 759 \\
\hline \multirow{2}{*}{$\begin{array}{ll}\text { Zelder I } \\
\text { II }\end{array}$} & $\ldots \ldots \ldots$ & 2 & 417 & 630 & 1126 & 1198 & 850 & $\overline{947}$ \\
\hline & & 51 & 445 & 720 & 1033 & 1302 & $\overline{1313}$ & 973 \\
\hline \multicolumn{9}{|c|}{ 13-1eavesgroup } \\
\hline \multirow{3}{*}{$\begin{array}{ll}\text { Petkuser } & \text { I } \\
& \text { II } \\
\text { II }\end{array}$} & $\ldots \ldots$ & 1 & 400 & 585 & 720 & 576 & 380 & 438 \\
\hline & $\ldots \ldots$ & 23 & 306 & 435 & 677 & 885 & $\overline{879}$ & 704 \\
\hline & & 24 & 395 & 590 & 882 & 1138 & 1245 & $1 \overline{1035}$ \\
\hline \multirow{2}{*}{$\begin{array}{l}\text { Zelder I } \\
\text { II }\end{array}$} & & 23 & 404 & 624 & 963 & 1211 & 1232 & 913 \\
\hline & & 21 & 453 & 675 & 897 & 1159 & 1273 & $1 \overline{009}$ \\
\hline \multicolumn{9}{|c|}{ 14-1 eaves group } \\
\hline \multirow{2}{*}{$\begin{array}{ll}\text { Petkuser I } & \text { II }\end{array}$} & $\ldots \ldots$ & 6 & 304 & 437 & 713 & 903 & 981 & 700 \\
\hline & & 8 & 382 & 555 & 847 & 1075 & 1242 & $\overline{1263}$ \\
\hline Zelder I .. & $\ldots$ & 5 & 457 & 602 & 903 & 1112 & 1334 & 1137 \\
\hline
\end{tabular}

FIg. 4. Surface area $\left(\mathrm{cm}^{2}\right)$ of the last six (or seven) leaves of plants with the same emergence rhythm in the Petkuser and Zelder varieties (the solid lines represent sub-groups with an initially slow leaf formation; at a later stage there is a catch-up effect)
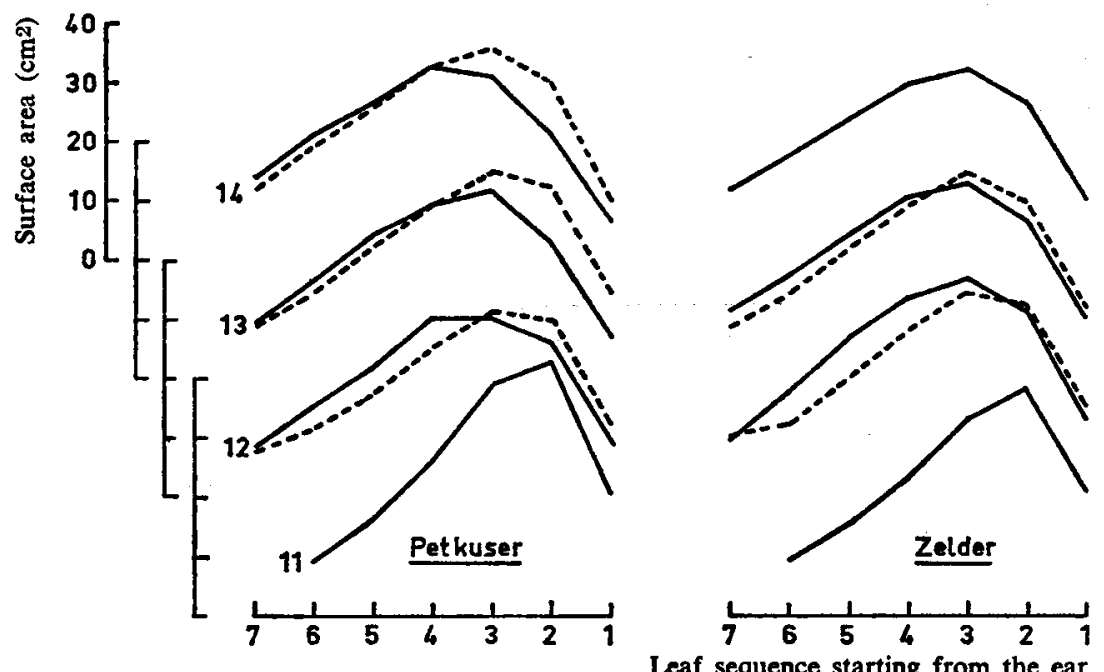
DIFFERENCE IN DEVELOPMENT RATE OF RYE IN RELATION TO NUMBER OF SPIKELETS PER EAR on according to the groups distinguished in TABLE 2

\begin{tabular}{|c|c|c|c|c|c|c|c|c|c|}
\hline \multicolumn{9}{|c|}{ Average leaf area in $\mathrm{mm}^{2}$ (leaf sequence $1-14$ ) } & \multirow{2}{*}{$\begin{array}{l}\text { Number of spike- } \\
\text { lets initiated }\end{array}$} \\
\hline 7 & 8 & 9 & 10 & 11 & 12 & 13 & 14 & total & \\
\hline 1602 & 2599 & 3881 & 4240 & 2028 & & & & 19978 & 35 \\
\hline 1504 & 2330 & 3303 & 3763 & 2098 & & & & 18420 & 34,3 \\
\hline 1507 & 2210 & 3014 & 3012 & 2635 & 946 & & & 17150 & 31,8 \\
\hline 1130 & 1771 & 2530 & 3109 & 2974 & 1217 & & & 17292 & 32,2 \\
\hline 1739 & 2688 & 3393 & 3697 & 3075 & 1277 & & & 21037 & 29 \\
\hline 1200 & 1996 & 2811 & 3445 & 3234 & 1482 & & & 19954 & 33 \\
\hline 840 & 1512 & 2364 & 2860 & 2717 & 1992 & 420 & & 15804 & 29 \\
\hline 973 & 1654 & 2417 & 2883 & 3125 & 2281 & 719 & & 17938 & 31,5 \\
\hline 914 & 1459 & 2214 & 2897 & 3480 & 3197 & 1434 & & 20880 & 34,1 \\
\hline$\overline{1147}$ & 1754 & 2430 & 3057 & 3343 & 2717 & 997 & & 20792 & 32,5 \\
\hline 855 & 1420 & 2206 & 2922 & 3433 & 3000 & 1235 & & 20537 & 33,7 \\
\hline 863 & 1357 & 2107 & 2650 & 3239 & 3081 & 2114 & 653 & 20102 & 30 \\
\hline 885 & 1212 & 1892 & 2586 & 3295 & 3539 & ․ 2993 & 1001 & 22767 & 34,8 \\
\hline$\overline{847}$ & 1206 & 1758 & 2382 & 2976 & 3217 & 2613 & 939 & 21483 & 33,2 \\
\hline
\end{tabular}

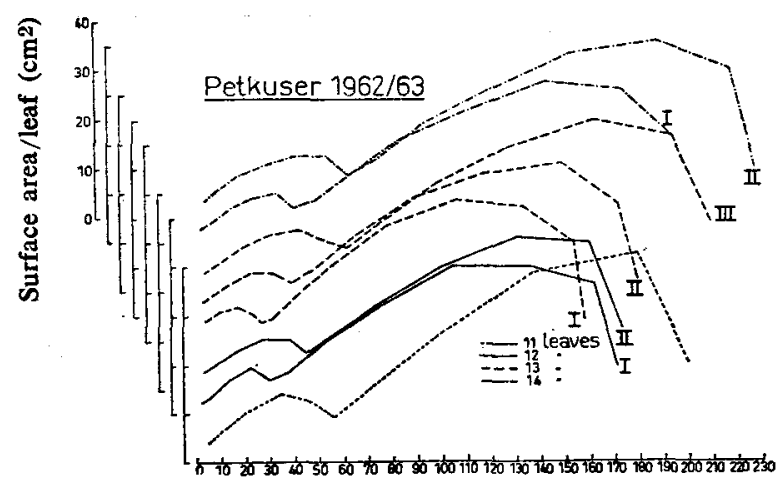

Sum total (summation) of leaf surface $\left(\mathrm{cm}^{2}\right)$

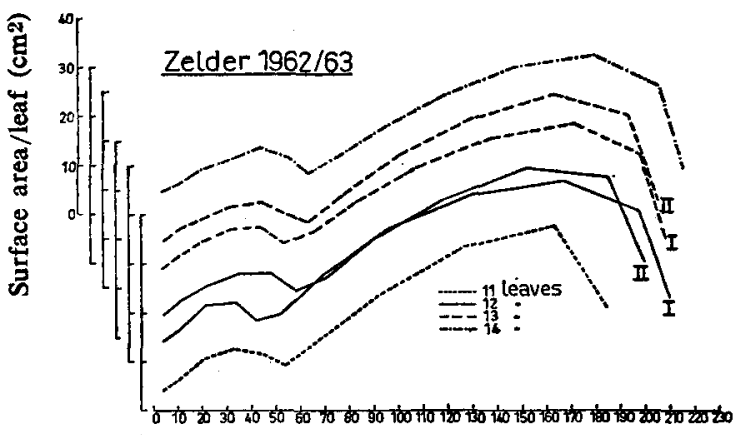

Sum total (summation) of leaf surface $\left(\mathrm{cm}^{2}\right)$
FiG. 5

Surface area per leaf $\left(\mathrm{cm}^{2}\right)$ plotted against the total leafsurface area of plants with the same emergence rhythm in the Petkuser and Zelder varieties; for groups represented by more than one line see FIG. 2 
TABLE 4. Average length of internodes and stalks $(\mathrm{mm})$; classification according to the groups distinguished in TABLE 2

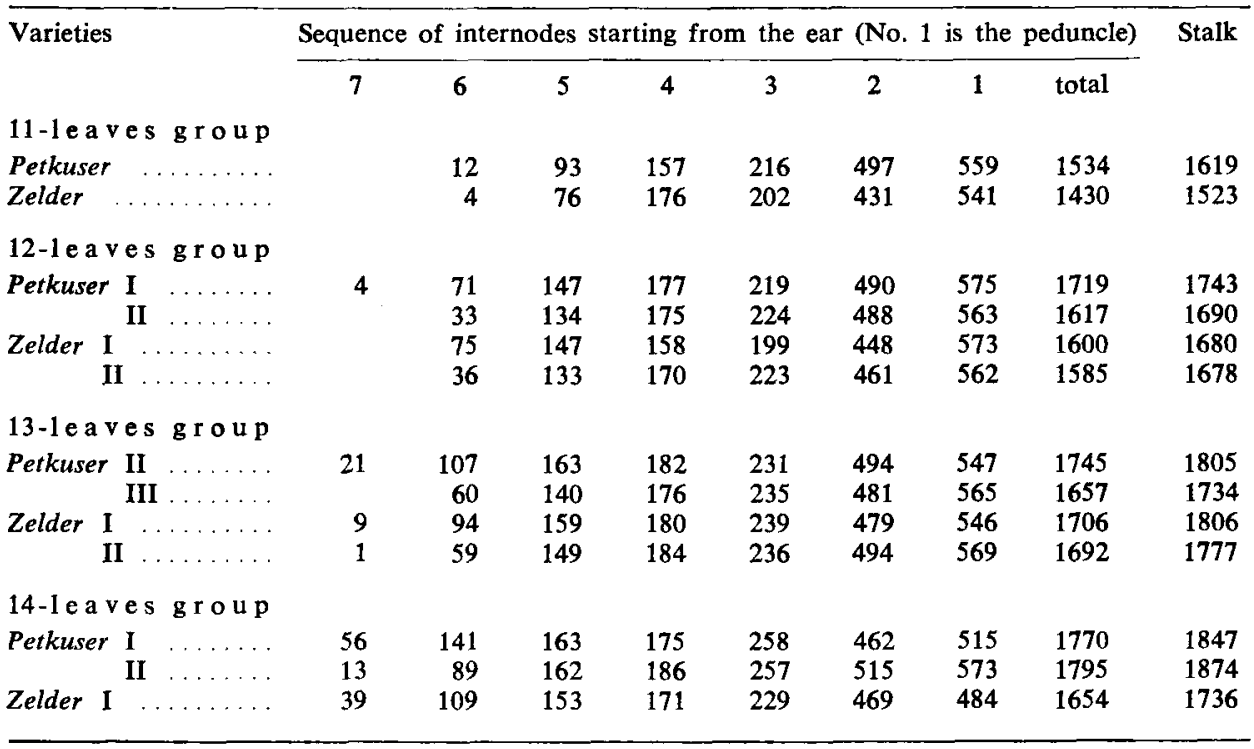

Table 5. Average length of the leaf sheaths ( $\mathrm{mm}$ ); classification according to the groups distinguished in TABLE 2

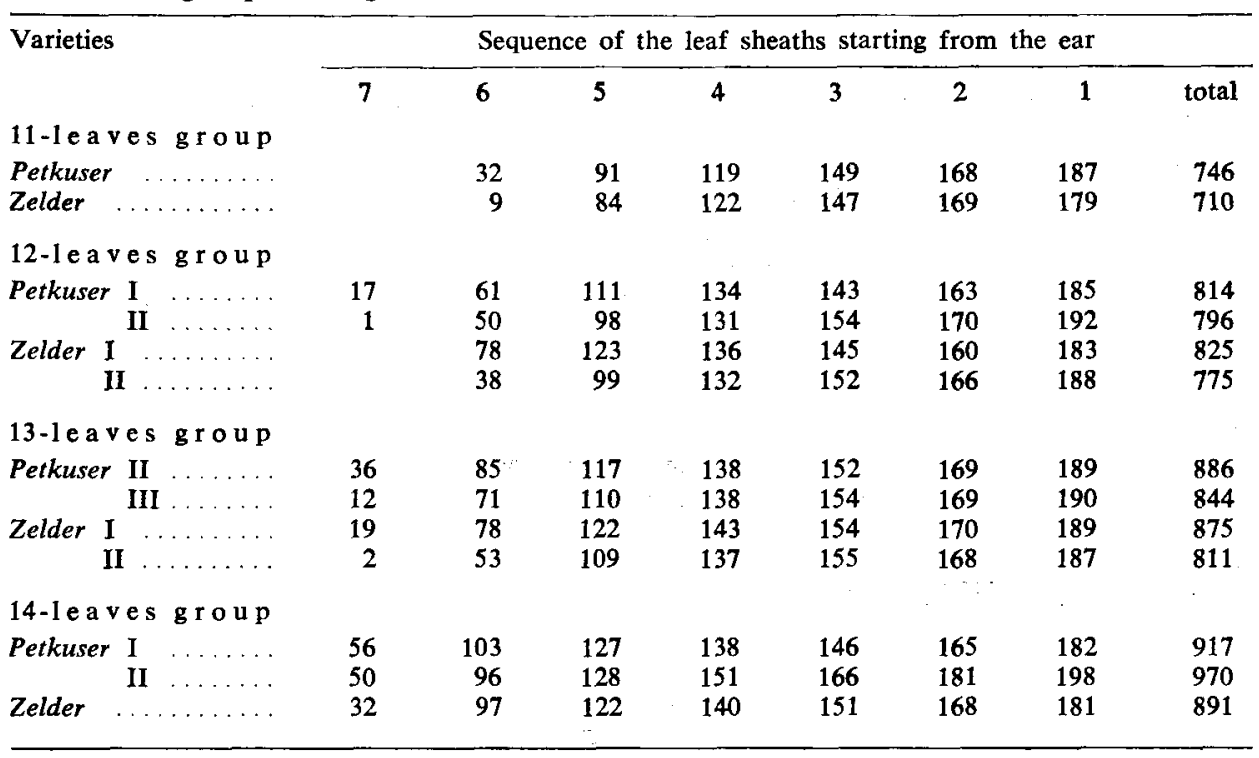


within one group with a given number of leaves increases with increasing size of the last leaves, i.e. as shown in 3.2. it increases with a decreasing leaf-emergence rate after the winter. But without further investigation it is impossible to establish whether this is a causal relationship, since in the comparison between the sub-groups with varying rhythm of emergence the emergence rate of the later leaves is closely bound up with the emergence rate of the early leaves appearing before the winter. Hence it is quite conceivable that the number of spikelets (which is, of course, determined in the early spring before heading is completed) is connected with the leafemergence rate up to that date.

\subsection{The lengths of internodes and leaf $\mathrm{sheaths}$}

So far as possible, for each leaf blade measured the accompanying sheath was also measured as well as the internode underneath; these measurements were, of course, confined to the post-winter period of growth. The results are shown in TABLES 4 and 5 in which the figures for the sub-groups with varying leaf-emergence rhythm are also separately listed.

The number of mensurable (i.e. visibly stretched) internodes and leaf sheaths increases with the number of leaves. This is also true of the average stalk length.

It was found that within a group of plants with the same number of leaves, the subgroup with a rapid post-winter leaf-emergence rate was found to have longer bottom internodes, although actually shorter top internodes than the sub-group with a slow leaf-emergence rate.

Fig. 6. Length (cm) of the last six (or seven) internodes of plants with the same emergence rhythm in the Petkuser and Zelder varieties; for the meaning of the solid lines see FIG. 4

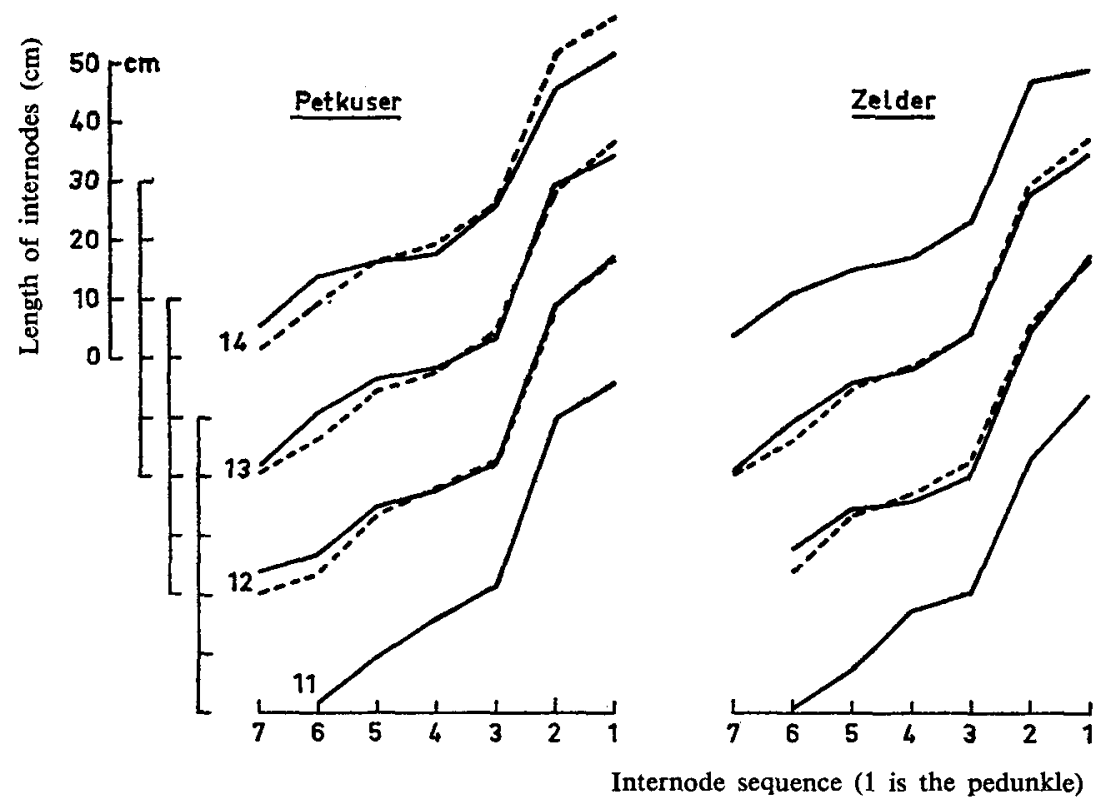


FIG. 7. Length (cm) of the last six (or seven) leaf sheaths of plants with the same emergence rhythm in the Petkuser and Zelder varieties; for the meaning of the solid lines see FIG. 4
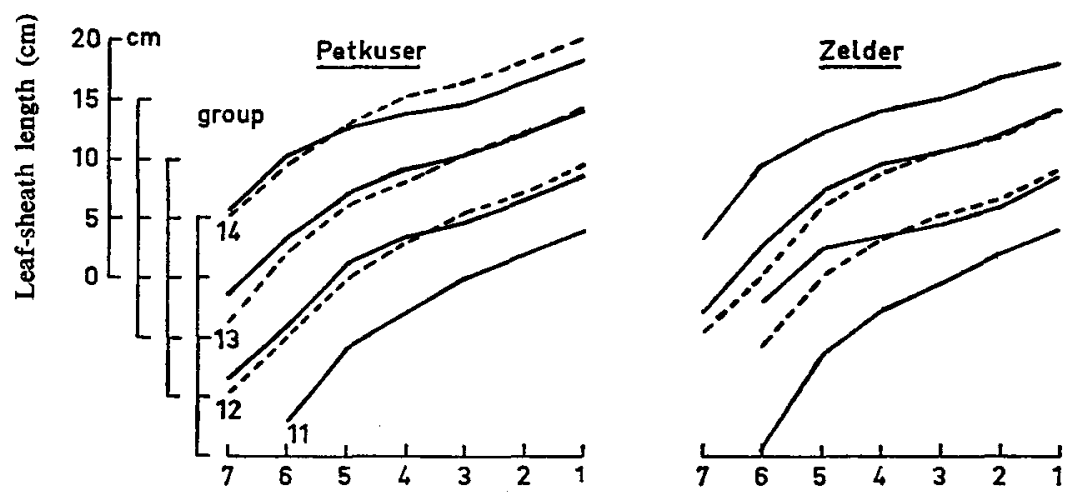

Sequence of leaf sheath starting from the ear

FIG. 8. Length $(\mathrm{cm})$ of the last six (or seven) internodes plotted against the surface area of the corresponding leaf of plants with the same total leaf number in the Petkuser and Zelder varieties

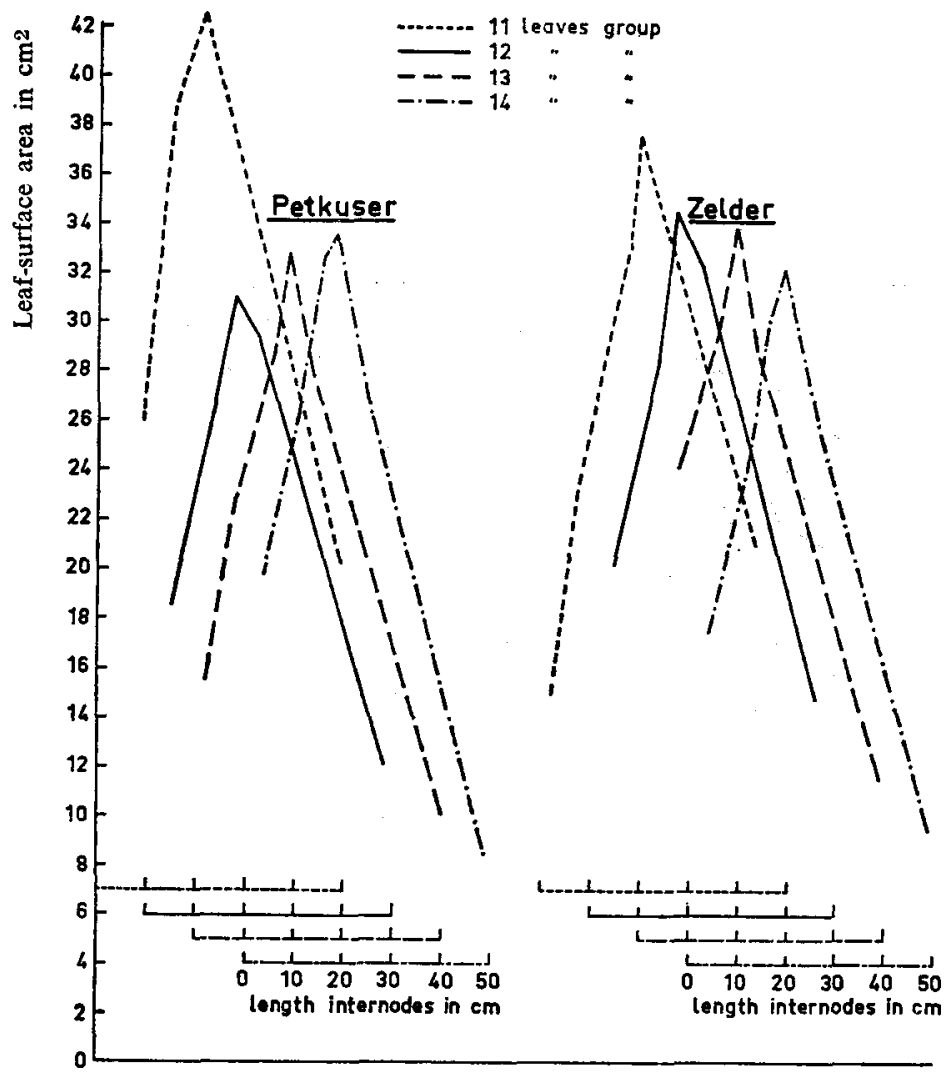


The lengths of the leaf sheaths exhibit the same general trends as the accompanying internodes, as is illustrated by FIGs. 6 and 7 .

When the lengths of the internodes are plotted against the surface area of the corresponding leaf it can be seen that the resultant line shows a very distinct kink (FIG. 8). The point at which this kink appears depends on the number of leaves on the plant in question. In the groups with 11 leaves it occurs at the 10th leaf, and in those with 12,13 and 14 leaves on the $10 \mathrm{th}, 11$ th and 12 th leaf respectively.

\section{REFERENCES}

Hoogland, R. F.

1961 Selection of rye by means of leaf counting. Euphytic. 10, $101-108$.

1962 Selection of rye by means of leaf counting. 2. Further data. Euphytica. 11, 209-212.

1964 Relation between leaf number and final leaf area of rye. Neth. J. agric. Sci. 12, 30-40.

ANIKIEV, V. V., and

1961 A new method for determining leaf surface area of cereals. F. F. Kutuzov Soc. Pl. Phys. 8, 293-295. 